the average suicide rate during the follow-up was around 8 per 100000 per year, but the yearly rate varied between 2 and 16 per 100 000. In 16 years 140 people committed suicide but none of these was from our series. In a four-year follow-up of all 42 patients in Nottingham with three or more admissions in the year 1990, there were two cases of suicide, one homicide, and a further patient committed suicide shortly after the follow-up period ended (Davies \& Payne, 1996). For a clinician, such a population of frequently admitted patients might be a better choice for the focusing of scarce resources. The case for blanket coverage of all first-admission patients remains without any evidence base.

Davies, S. \& Payne, S. (1996) Patients repeatedly admitted to psychiatric wards: a four-year follow-up. Psychiatric Bulletin. 20. 342-344.

Gunnel, D. Frankel, S. (1994) Prevention of suicide: aspirations and evidence. British Medical Journal, 308. 1227-1233.

Hamsen, V., Arnesen, E. \& Jecobsen, B. K. (1997) Total mortality in people admitted to a psychiatric hospital. British journal of Psychiatry. 170. 186-190.

A. S. Lee Academic Department of Psychiatry, University Hospital, Nottingham NG2 2VH

P. C. Naik Lyndon Resources Centre, Solihull, West Midlands B92 8PW

S. Davies Towers Hospital, Leicester

A. Buckley Queen Elizabeth Psychiatric Hospital, Edgbaston, Birmingham

\section{Transcending barriers between religion and psychiatry}

Sir: George Carey (1997) suggests there is common ground to be shared by us, and it is my belief that here is an opportunity to collate knowledge and experience, and combine our resources. The hope would be to make progress in those 'Cinderella' disorders which at present tend to receive such curt treatment in our clinics.

There are pools of suffering individuals with 'broken' personalities, in places that are accessible to both disciplines. As a Christian psychiatrist, I have met with many people who have given their lives to Jesus as a result of such agonising situations that have resulted from their self-driven wills. Personalities that have quite simply given up the fight. Some of them have done so during times of reflection in prison. Others are addicts who have reached their turningpoint at the 'rock-bottom' of their lives.
Alcoholics Anonymous and other 12step fellowships have been uniquely successful in giving back the lives to millions of sufferers worldwide whose options would otherwise have been either more oblivion or suicide. Those in recovery have made a decision, through recognition of their powerlessness and folly of their self-will, that they needed to hand over their lives to God and begin to walk a different path.

We know that many personality-disordered patients are victims of abuse in childhood, with no experience of a loving father in their tender years, and consequently no adequate sense of moral values. This is where I have seen the healing ministry in its element, taking the souls of the lost and weary and giving hope with a new set of values and a new family - the Church with all the essentials of unconditional love, forgiveness and nurturing that these vulnerable people so badly need.

Carey, G. (1997) Towards wholeness: transcending the barriers between religion and psychiatry. British Journal of Psychiotry, 170, 396-397.

White, J. (1991) Changing on the Inside. London: Eagle

D. Roberts New Covenant Church, Lox Lane Farm, Shaftesbury, Dorset SP7 9PU

\section{Gender and age at onset of schizophrenia}

Sir: Jablensky \& Cole (1997) have confused cause and consequence in suggesting that the gender differences in age at onset of schizophrenia are a result of marital status. The age at which symptoms begin and gender difference in onset are important clues to the underlying biological nature of the disorder (DeLisi, 1992). Jablensky \& Cole suggest that marriage somehow delays onset of the illness, supporting this concept with data showing that married males and females do not differ in age at onset of schizophrenia. However, they fail to explain why this effect is more relevant for males than females, and why unmarried males still have an earlier age at onset than unmarried females.

Females marry at an earlier age than males, due not only to their level of brain development, and also to different reasons for mate choice. Females favour males who are more established, independent and can care for them, whereas mate choice in males has more to do with physical attrac- tion than abilities. Thus, males, unlike females, must achieve a certain level of independence with academic and social success prior to marriage, whereas females may be dependent on parental care-taking until they marry and transfer this role to a spouse. A measure of ability to live independently is an indication of premorbid functioning prior to the onset of psychotic symptoms. One would then expect, given what is known about the development of schizophrenia, that males who have a vulnerability for schizophrenia would be less likely to marry than females, and if they did marry, they would belong to a select group of 'late-onset' males, whereas females are more likely to marry regardless of premorbid level of functioning.

Thus, the 'married' group of schizophrenics will contain both early- and late-onset females and only late-onset males, skewing the data toward no difference in age at onset between males and females. In Jablensky \& Cole's analysis, single males have an earlier age at onset than single females - consistent with the notion that neither may have gained a degree of independence, but other factors affect age at onset. The authors fail to take the above into consideration and thus have not convincingly dispelled the notion that marital status is a consequence of age at onset of schizophrenia and that gender differences in age at onset suggest an underlying biological process, perhaps indicating a role for the sex chromosomes (Crow, 1995).

Crow, T. J. (1995) Aetiology of schizophrenia: an evolutionary view. International Clinical Psychopharmocology, 10 (suppl. 3). 49-56.

DeLisi, L. E. (1992) The significance of age of onset for schizophrenia. Schizophrenia Bulletin, 18, 209-215.

- (1997) Is schizophrenia a lifetime disorder of brain plasticity, growth and aging? Schizophrenio Research, 23, 119-129.

Jablensky, A. \& Cole, S. W. (1997) Is the earlier age at onset of schizophrenia in males a confounded finding? Results from a cross-cultural investigation. British Journal of Psychiotry. 170. 234-240.

L. E. DeLisi Stony Brook Health Sciences Center, School of Medicine. Department of Psychiatry \& Behavioral Science, State University of New York at Stony Brook, Stony Brook, NY I1794-810I, USA

\section{War pensions}

Sir: Significant mental health problems as a result of the Second World War are commonplace for European clinicians 